\title{
Spleen transient elastography predicts actuarial survival after liver transplantation
}

\author{
Kilian Friedrich ${ }^{1}$, Arianeb Mehrabi ${ }^{2}$, Jan Pfeiffenberger ${ }^{1}$, Christian Rupp ${ }^{1}$, Karl Heinz Weiss ${ }^{1}$, \\ Markus Mieth ${ }^{2}$
}

${ }^{1}$ Department of Gastroenterology and Hepatology, University Hospital of Heidelberg, Heidelberg, Germany; ${ }^{2}$ Department of General, Visceral and Transplantation Surgery, University Hospital of Heidelberg, Heidelberg, Germany

Contributions: (I) Conception and design: K Friedrich, M Mieth, KH Weiss; (II) Administrative support: J Pfeiffenberger; (III) Provision of study materials or patients: K Friedrich, KH Weiss, C Rupp, J Pfeiffenberger; (IV) Collection and assembly of data: K Friedrich, KH Weiss, M Mieth, A Mehrabi; (V) Data analysis and interpretation: K Friedrich, A Mehrabi; (VI) Manuscript writing: All authors; (VII) Final approval of manuscript: All authors.

Correspondence to: Karl Heinz Weiss. Department of Gastroenterology and Hepatology, University Hospital of Heidelberg, Im Neuenheimer Feld 410, 69120 Heidelberg, Germany. Email: Karl-Heinz.Weiss@med.uni-heidelberg.de.

Background: Splenic transient elastography (TE) correlates with increased portal pressure. Little data are available in the post liver transplantation (LTx) setting.

Methods: Three months after LTx, we performed splenic TE in 125 LTx recipients.

Results: Mean splenic TE values were 29.4 ( \pm 6.3 ; range, 21.6-49.2) kPa. Splenic TE correlated with reduced time to development until persistent ascites (30 events, OR =1.082, 95\% CI: 1.034-1.133; P=0.001), hepatorenal syndrome ( 8 events, $\mathrm{OR}=1.109,95 \% \mathrm{CI}: 1.015-1.211 ; \mathrm{P}=0.022$ ) and hepatic encephalopathy (16 events, $\mathrm{OR}=1.136,95 \% \mathrm{CI}: 1.066-1.211 ; \mathrm{P}=0.000)$. In Cox univariate analysis, splenic TE served as a predictor of actuarial survival free of liver $(\mathrm{OR}=1.114,95 \% \mathrm{CI}: 1.050-1.182 ; \mathrm{P}<0.001)$ and remained an independent risk factor associated with reduced actuarial survival free of LTx in multivariate analysis (OR =1.103, 95\% CI: $1.026-1.186 ; \mathrm{P}=0.008)$.

Conclusions: Splenic TE measurement at 3 months after LTx serves as a robust predictor of survival in LTx recipients.

Keywords: Spleen; liver transplantation (LTx); transient elastography (TE); survival

Received: 27 November 2019; Accepted: 12 May 2020; Published: 25 July 2022.

doi: $10.21037 /$ tgh-19-343

View this article at: http://dx.doi.org/10.21037/tgh-19-343

\section{Introduction}

Transient elastography (TE) is a widely available method that was initially designed to assess hepatic stiffness (1-3). Liver TE measurement accurately estimates the presence of advanced fibrosis and cirrhosis in patients with chronic liver disease (4). However, recent studies further showed that spleen stiffness, measured by transient elastography correlates with hepatic venous pressure gradient (5-8). Therefore, splenic elastography was shown to identify clinically significant portal hypertension (9-12). Increased spleen stiffness in patients with liver cirrhosis has been attributed to splenic tissue hyperplasia and splenic lymphoid activation $(13,14)$. However, increased portal pressure and the associated hyperdynamic circulation have been suggested as predominant factors for spleen stiffness (15). In the post liver transplantation (LTx) setting, portal hypertension constitutes a significant and severe complication, resulting in a highly increased mortality (16). The etiology of increased portal pressure after LTx ranges from portal vein thrombosis/anastomotic stenosis to graft rejection and recurrent liver fibrosis and cirrhosis of the transplanted graft (17-19). At present, there are only few descriptive studies investigating spleen elastography after 
LTx (12). These descriptive studies showed that spleen elastography is elevated before LTx and declines after LTx. At present, there are no information available as to what extend spleen elastography predicts complications or survival following LTx. In this present study, we performed splenic TE routinely 3 months after LTx and investigated its predictive value upon further clinical outcome.

\section{Methods}

\section{Study design}

This is a retrospective analysis of a prospective study cohort. The prospective study cohort started in October 2012. All medical data from the time of enrolment at Eurotransplant were recorded for each patient. Informed consent to participate in the study was obtained from each patient. The study was approved by the Ethical Committee of the University of Heidelberg (No. S-270/2015) and carried out in accordance with the Declaration of Helsinki (as revised in 2013). Clinical data presented in this study were retrospectively analyzed during the time from October 2012 until October 2018. Following LTx, patients were discharged from our hospital and routinely scheduled for an outpatient visit at our clinic 3 months after LTx. At this time, laboratory markers were evaluated and splenic TE was performed. Patients with complicated postoperative course, who couldn't be discharged after 3 months were excluded from our study. Patients with splenectomy, portal thrombosis, liver thrombosis or coiling of the splenic artery before or after LTx were not included to the study.

\section{Endpoint definition and scoring calculation}

Actuarial survival free of LTx was defined as either death or recurrent LTx (Re-LTx) as endpoints.

APRI-score (AST-to-platelet radio index) was calculated using the formula (20):

$\mathrm{APRI}=100 \times \mathrm{AST} /($ upper limit of normal for AST $\times$

platelets, $\times 10^{9} / \mathrm{L}$ )

FIB-4 score (fibrosis-4 score) was calculated using the following formula (21):

$$
\begin{aligned}
& \text { FIB-4 }=\text { age }(\text { years }) \times \operatorname{AST}(\mathrm{U} / \mathrm{L}) /\left[\text { platelets }\left(10^{9} / \mathrm{L}\right) \times\right. \\
& 1 / 2 \operatorname{ALT}(\mathrm{U} / \mathrm{L})]
\end{aligned}
$$

Hepatic decompensation of patients on the LTx list was assessed by documenting the occurrence of hydropic decompensation requiring paracentesis or forced diuretic treatment, hepatic encephalopathy $\geq$ grade II, according to West Haven Criteria, and hepatorenal syndrome, according to EASL guidelines (22).

\section{Transient elastography}

For the TE measurement of spleen stiffness, a FibroScan (Echosens, Paris, France) was used. This device creates a low-frequency acoustic wave to an ultrasonic transducer. We measure its speed first with an ultrasound imaging, and using the measured speed, the tissue's stiffness is computed where the acoustic wave penetrates (23). The result was expressed in kilopascal $(\mathrm{kPa})$ and all examinations were performed using the standard probe ( $M$ probe). In order to measure splenic stiffness, patients were lying on their backs with their left arms raised to their heads. The probe was placed vertically on the intercostal skin of the spleen. The lung area and intercostal areas were avoided when using FibroScan's ultrasonic TM mode (time-motion) and A-mode (amplitude mode) images. The measurements were ended when 10 successful values had been obtained for each patient. Stiffness was determined as the average value of the 10 measurements, after excluding the highest and the lowest values. The success rate was defined as the number of successful results divided by the total number of examinations.

\section{Statistical analysis}

Preliminary testing for normality was conducted by using the Shapiro-Wilk test. If the preliminary test for normality is not significant, the $t$-test is used; if the preliminary test rejects the null hypothesis of normality, a nonparametric test (Mann-Whitney's U test) is applied in the main analysis (24). Spearman's rho was used as the nonparametric measure of statistical dependence between two variables. The actuarial survival free of LTx rate was estimated using Cox univariate/multivariate analysis. Differences between the actuarial estimates were analyzed using the log-rank test. The following variables were selected for univariate analysis based on results of previous studies: age, gender, body mass index, presence of metabolic co-diseases (diabetes, hypertriglyceridemia, hypercholesterolemia), splenic TE, serum alanine aminotransferase (ALT), aspartate aminotransferase (AST), gamma-glutamyl transferase (GGT), alkaline phosphatase (AP), bilirubin, albumin, creatinine, international normalized ratio (INR) and 
Table 1 Patient characteristics 3 months after LTx

\begin{tabular}{|c|c|}
\hline Characteristics & Value \\
\hline Spleen elastography $(\mathrm{kPA})$, mean $\pm \mathrm{SD}$ & $29.9 \pm 6.3$ \\
\hline AST (U/L), mean \pm SD & $41.1 \pm 48.9$ \\
\hline ALT (U/L), mean \pm SD & $56.9 \pm 75.5$ \\
\hline GGT $(U / L)$, mean \pm SD & $168.3 \pm 243.7$ \\
\hline $\mathrm{AP}(\mathrm{U} / \mathrm{L})$, mean $\pm \mathrm{SD}$ & $157.0 \pm 141.7$ \\
\hline Bilirubin $(\mathrm{mg} / \mathrm{dL})$, mean $\pm \mathrm{SD}$ & $1.00 \pm 1.4$ \\
\hline Thrombocytes $(/ \mathrm{nL})$, mean $\pm \mathrm{SD}$ & $177.8 \pm 92.1$ \\
\hline INR mean, SD & $1.06 \pm 0.2$ \\
\hline Albumin (g/dL), mean $\pm S D$ & $3.8 \pm 0.6$ \\
\hline Creatinine $(\mathrm{mg} / \mathrm{dL})$, mean $\pm \mathrm{SD}$ & $1.0 \pm 0.6$ \\
\hline Metabolic co-disease, n (\%) & $67 / 125(53.6)$ \\
\hline Age at LTx (years), mean \pm SD & $48.3 \pm 13.2$ \\
\hline Gender & $\begin{array}{c}38 \text { females, } \\
87 \text { males }\end{array}$ \\
\hline $\mathrm{BMI}\left(\mathrm{kg} / \mathrm{m}^{2}\right)$, mean $\pm \mathrm{SD}$ & $26.5 \pm 5.3$ \\
\hline APRI-score, mean \pm SD & $0.66 \pm 1.09$ \\
\hline FIB-4 score, mean \pm SD & $2.13 \pm 2.03$ \\
\hline Immunosuppressive agent & $\begin{array}{c}\text { Ciclosporin: } n=70 \\
(56.0 \%) ; \text { tacrolimus } \\
n=55(44.0 \%)\end{array}$ \\
\hline
\end{tabular}

LTx, liver transplantation; AST, aspartate aminotransferase; ALT, alanine aminotransferase; GGT, gamma-glutamyl transferase; AP, alkaline phosphatase; INR, international normalized ratio; APRI-score, AST-to-platelet radio index; FIB-4 score, fibrosis-4 score.

thrombocytes. A $\mathrm{P}$ value of $<0.1$ in univariate analysis was defined for variables to be included in a Cox's proportional hazards model, using a stepwise procedure with a threshold of $\alpha=0.05$. Statistical analysis was performed using SPSS version 25.0 software (SPSS Inc., Chicago, USA), and significance was accepted for values of $\mathrm{P}<0.05$.

\section{Results}

\section{LTx cohort}

Of the 125 liver transplanted patients, 38 were female $(30.4 \%)$ and 87 were male (69.6\%). The underlying hepatic disorders contributing to LTx were: alcoholic liver disease (ALD, $\mathrm{n}=24)$, chronic hepatitis B (HBV, $\mathrm{n}=10)$, chronic hepatitis $\mathrm{C}(\mathrm{HCV}, \mathrm{n}=30)$, primary sclerosing cholangitis
(PSC, $\mathrm{n}=19$ ), non-alcoholic steatohepatitis (NASH, $\mathrm{n}=8$ ), and other hepatic disorders $(\mathrm{n}=34$, each subgroup $\mathrm{n}<10)$. Mean follow-up time was $18.3 \pm 16.0$ (range, 0.35-85.3) months. Nine patients received Re-LTx while 9 patients died in the course after LTx. Serological markers, APRI/ FIB-4-scores and clinical data 3 months after LTx are shown in Table 1.

\section{Distribution of splenic TE 3 months after LTX}

Mean transient splenic elastography values 3 months after LTx was $29.4( \pm 6.3$; range, $21.6-49.2) \mathrm{kPa}$.

\section{Splenic TE reflects liver enzymes 3 months after LTx}

There was a statistically significant positive correlation between TE and AST $(\mathrm{P}=0.028$, Pearson correlation coefficient: 0.197), GGT ( $\mathrm{P}=0.028$, Pearson correlation coefficient: 0.197$)$, bilirubin $(\mathrm{P}>0.000$, Pearson correlation coefficient: 0.362$)$. This correlation was not observed for ALT $(\mathrm{P}=0.084)$, AP $(\mathrm{P}=0.362)$, INR $(\mathrm{P}=0.292)$, albumin $(\mathrm{P}=0.701)$, creatinine $(\mathrm{P}=0.595)$ and thrombocytes $(\mathrm{P}=0.059)$.

\section{Clinical complications after LTX}

The cause of death for the 9 deceased patients were all hepatic and/or transplant related (recurrent liver disease in 4 patients, non-anastomotic biliary strictures in 2 patients, chronic rejection in 1 patient, recurrence of hepatocellular carcinoma in 2 patients). Hepatic decompensation occurred in 26 patients over the course of follow-up. Mean time until development of hepatic decompensation was $11.4 \pm 13.7$ months after the time of splenic TE measurement.

\section{TE and clinical complications after LTX}

At 3 months post LTx, TE values did not correlate with development of acute liver rejection (34 events, $\mathrm{OR}=1.013$, 95\% CI: $0.953-1.077 ; \mathrm{P}=0.682)$ or development of biliary stenosis (57 events, OR $=1.043$, 95\% CI: 0.991-1.098; $\mathrm{P}=0.109)$ during further follow-up.

However, we observed a highly significant correlation for splenic TE and reduced time to development of persistent ascites (30 events, OR $=1.082$, 95\% CI: 1.034-1.133; $\mathrm{P}=0.001$ ), hepatorenal syndrome ( 8 events, $\mathrm{OR}=1.109,95 \%$ CI: $1.015-1.211 ; \mathrm{P}=0.022)$ and hepatic encephalopathy (16 events, $\mathrm{OR}=1.136,95 \%$ CI: $1.066-1.211 ; \mathrm{P}=0.000$ ). 
Table 2 Features associated with death/recurrent LTx in patients 3 months after LTx according to Cox's proportional hazards model

\begin{tabular}{|c|c|c|c|c|}
\hline Features & \multicolumn{2}{|c|}{ Cox univariate analysis } & \multicolumn{2}{|c|}{ Cox multivariate analysis } \\
\hline Splenic TE (kPA) & $1.114(1.050-1.182)$ & 0.001 & $1.103(1.026-1.186)$ & 0.008 \\
\hline AST (U/L) & $1.007(1.001-1.014)$ & 0.032 & $1.000(0.992-1.007)$ & 0.933 \\
\hline Bilirubin (mg/dL) & $1.241(1.064-1.448)$ & 0.006 & $1.120(0.922-1.587)$ & 0.169 \\
\hline Thrombocytes (/nL) & $0.993(0.986-1.000)$ & 0.057 & $0.993(0.986-1.000)$ & 0.053 \\
\hline INR & $0.647(0.059-7.040)$ & 0.721 & NA & NA \\
\hline albumin (g/dL) & $0.974(0.905-1.048)$ & 0.475 & NA & NA \\
\hline Creatinine (mg/dL) & $1.172(0.594-2.313)$ & 0.647 & NA & NA \\
\hline BMI $\left(\mathrm{kg} / \mathrm{m}^{2}\right)$ & $1.024(0.937-1.119)$ & 0.598 & NA & NA \\
\hline
\end{tabular}

LTx, liver transplantation; TE, transient elastography; AST, aspartate aminotransferase; INR, international normalized ratio.

\section{Transient liver elastography predicts actuarial survival after LTX}

Age at LTx, gender, BMI, metabolic co-disease, splenic TE, serum AST, serum bilirubin, serum creatinine, serum albumin, INR, thrombocytes were subjected to Cox univariate analysis (Table 2). Metabolic co-disease (OR $=0.389,95 \%$ CI: $0.146-1.039 ; \mathrm{P}=0.060)$, TE $(\mathrm{OR}=1.114$, 95\% CI: $1.050-1.182 ; \mathrm{P}<0.001)$, serum AST $(\mathrm{OR}=1.007$, 95\% CI: 1.001-1.014; $\mathrm{P}=0.032$ ), serum bilirubin (OR $=1.241,95 \%$ CI: $1.064-1.448 ; \mathrm{P}=0.006)$ and thrombocytes ( $\mathrm{OR}=0.993,95 \%$ CI: 0.986-1.000; $\mathrm{P}=0.057)$ were below the set $\mathrm{P}$ value of 0.1 and therefore subjected to further multivariate analysis. In multivariate analyses, splenic TE remained an independent risk factor associated with reduced actuarial survival free of $\mathrm{LTx}(\mathrm{OR}=1.103,95 \% \mathrm{CI}$ : 1.026-1.186; $\mathrm{P}=0.008$; Table 2).

Using ROC-analysis, the optimal cut-off value to predict actuarial survival in our study cohort would be a splenic TE value of 32.4. This cut-off value would lead to a sensitivity of 0.789 and a specificity of 0.722 (ROC: 0.781 , Figure 1).

\section{Transient liver elastography predicts actuarial survival independent of established liver fibrosis scores (APRI or FIB-4 score)}

Splenic TE $v s$. APRI-score: in univariate analysis, APRIscore was below the set cut-off value of $\mathrm{P}<0.1$ to predict actuarial survival free of LTx $(\mathrm{OR}=1.267,95 \% \mathrm{CI}$ : 0.961-1.670; $\mathrm{P}=0.093)$. When subjected to multivariate analysis along with splenic TE remained as an independent predictor of survival (OR $=1.113,95 \%$ CI: 1.044-1.186; $\mathrm{P}=0.001)$ while APRI-score $\operatorname{did}$ not $(\mathrm{OR}=1.012,95 \% \mathrm{CI}$ : 0.727-1.408; $\mathrm{P}=0.943)$.

Splenic TE vs. FIB-4 score: in univariable analysis, the FIB-4 score met the prespecified threshold of significance of $<0.1$ for actuarial survival free of LTx $(\mathrm{OR}=1.188,95 \%$ CI: $1.019-1.384 ; \mathrm{P}=0.028$ ).

After multivariable analysis, splenic TE remained an independent predictor of survival $(\mathrm{OR}=1.103,95 \% \mathrm{CI}$ : 1.033-1.178; $\mathrm{P}=0.004)$ while FIB-4 $\operatorname{did}$ not $(\mathrm{OR}=1.063$, 95\% CI: 0.888-1.272; $\mathrm{P}=0.505)$.

\section{Discussion}

While TE of the liver is widely incorporated in screening protocols of liver disease patients $(4,25,26)$, splenic TE has been shown to correlate with increased portal pressure $(5,6)$ and recently been implemented in variceal screening protocols in patients with compensated liver cirrhosis (27). However, no data are available to what degree splenic TE measurement provides meaningful data in the specific setting after LTx, particularly in the context of a predictive marker of patient survival. In this prospective study cohort, we measured splenic TE routinely 3 months after LTx, with 


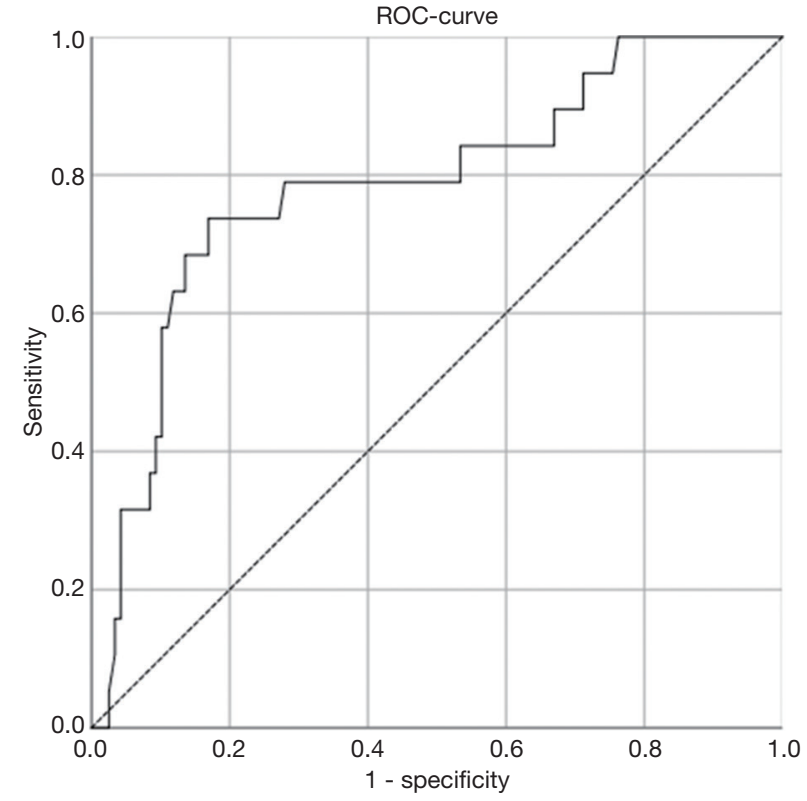

Figure 1 ROC analysis of splenic TE measurement and actuarial survival. ROC, receiver operating characteristic; TE, transient elastography.

a mean follow-up time of 18 months.

Chin et al. reported that after LTx the density of the spleen reduced to $41.9 \mathrm{kPa}$ in the second week and to $32.9 \mathrm{kPa}$ in the fourth to eighth week (12), therefore showing comparable results with our splenic TE measurements 3 months after LTx $(29.4 \pm 6.3 \mathrm{kPa})$. At 3 months following LTx, splenic TE correlated with serological markers of liver function (AST, GGT and bilirubin). As splenic TE identifies portal hypertension (9), it is interesting that splenic TE measurement after LTx significantly correlated with time to development until development of persistent ascites, hepatorenal syndrome and overt hepatic encephalopathy. Furthermore, splenic TE correlated with actuarial survival free of LTx and, in direct comparison surpassed liver fibrosis scores such as FIB-4 or APRI regarding the predictive value of actuarial survival free of LTx.

Following LTx, diagnosis of portal hypertension identifies patients of high-risk requiring particular medical attention. However, diagnosis of portal hypertension after LTx is challenging, particularly due to vascular changes prior to LTx. The definitive diagnosis of portal hypertension can only be established by invasive direct portal pressure measurement, which is therefore not routinely performed and inept as a predictive tool. In our present study, we propose splenic TE to function as an easily performable, non-invasive test in liver transplanted patients, that can significantly identify patients at high risk for reduced actuarial survival. There several limitations to this study. Although this is a prospective study cohort, the data analysis was performed retrospectively. Furthermore, splenic TE measurement was routinely only performed 3 months after LTx and not repeatedly at standardized times. Therefore, no data is available how changes in contrast to baseline splenic TE would mean for the transplanted patient.

In the present study, we were able to show that splenic TE measurement at 3 months after LTx, adequately serves as a predictor of actuarial survival free of LTx. Therefore, TE measurement should be implemented in the post LTx workup to identify transplanted patients at risk that need further medical attention.

\section{Acknowledgments}

We are grateful to the patients and their families. We thank Mrs. Klöters-Plachky and Mrs. Leopold for excellent technical assistance.

Funding: None.

\section{Footnote}

Data Sharing Statement: Available at https://tgh.amegroups. com/article/view/10.21037/tgh-19-343/dss

Conflicts of Interest: All authors have completed the ICMJE uniform disclosure form (available at https://tgh.amegroups. com/article/view/10.21037/tgh-19-343/coif). The authors have no conflicts of interest to declare.

Ethical Statement: The authors are accountable for all aspects of the work in ensuring that questions related to the accuracy or integrity of any part of the work are appropriately investigated and resolved. All medical data from the time of enrolment at Eurotransplant were recorded for each patient. Informed consent to participate in the study was obtained from each patient. The study was approved by the Ethical Committee of the University of Heidelberg (No. S-270/2015) and carried out in accordance with the Declaration of Helsinki (as revised in 2013).

Open Access Statement: This is an Open Access article distributed in accordance with the Creative Commons Attribution-NonCommercial-NoDerivs 4.0 International License (CC BY-NC-ND 4.0), which permits the non- 
commercial replication and distribution of the article with the strict proviso that no changes or edits are made and the original work is properly cited (including links to both the formal publication through the relevant DOI and the license). See: https://creativecommons.org/licenses/by-nc-nd/4.0/.

\section{References}

1. Foucher J, Chanteloup E, Vergniol J, et al. Diagnosis of cirrhosis by transient elastography (FibroScan): a prospective study. Gut 2006;55:403-8.

2. Sandrin L, Fourquet B, Hasquenoph JM, et al. Transient elastography: a new noninvasive method for assessment of hepatic fibrosis. Ultrasound Med Biol 2003;29:1705-13.

3. Ziol M, Handra-Luca A, Kettaneh A, et al. Noninvasive assessment of liver fibrosis by measurement of stiffness in patients with chronic hepatitis C. Hepatology 2005;41:48-54.

4. Tsochatzis EA, Gurusamy KS, Ntaoula S, et al. Elastography for the diagnosis of severity of fibrosis in chronic liver disease: a meta-analysis of diagnostic accuracy. J Hepatol 2011;54:650-9.

5. Radu C, Stefanescu H, Procopet B, et al. Is spleen stiffness a predictor of clinical decompensation in cirrhotic patients? J Gastrointestin Liver Dis 2014;23:223-4.

6. Stefanescu H, Grigorescu M, Lupsor M, et al. Spleen stiffness measurement using Fibroscan for the noninvasive assessment of esophageal varices in liver cirrhosis patients. J Gastroenterol Hepatol 2011;26:164-70.

7. Stefanescu H, Marasco G, Calès P, et al. A novel spleendedicated stiffness measurement by FibroScan ${ }^{\circledR}$ improves the screening of high-risk oesophageal varices. Liver Int 2020;40:175-85.

8. Stefanescu H, Procopet B, Platon-Lupsor M, et al. Is there any place for spleen stiffness measurement in portal hypertension? Am J Gastroenterol 2013;108:1660-1.

9. Jansen C, Bogs C, Verlinden W, et al. Shear-wave elastography of the liver and spleen identifies clinically significant portal hypertension: a prospective multicentre study. Liver Int 2017;37:396-405.

10. Chin JL, Chan G, McCormick PA. Spleen stiffness: the new kid on the block for diagnosing portal hypertension? Gastroenterology 2013;144:1152-3.

11. Chin JL, Chan G, Ryan JD, et al. Why is spleen stiffness better at predicting large esophageal varices and variceal bleeders? Am J Gastroenterol 2014;109:134.

12. Chin JL, Chan G, Ryan JD, et al. Spleen stiffness can noninvasively assess resolution of portal hypertension after liver transplantation. Liver Int 2015;35:518-23.

13. Bolognesi M, Merkel C, Sacerdoti D, et al. Role of spleen enlargement in cirrhosis with portal hypertension. Dig Liver Dis 2002;34:144-50.

14. Mejias M, Garcia-Pras E, Gallego J, et al. Relevance of the mTOR signaling pathway in the pathophysiology of splenomegaly in rats with chronic portal hypertension. J Hepatol 2010;52:529-39.

15. Sharma P, Mishra SR, Kumar M, et al. Liver and spleen stiffness in patients with extrahepatic portal vein obstruction. Radiology 2012;263:893-9.

16. Duffy JP, Hong JC, Farmer DG, et al. Vascular complications of orthotopic liver transplantation: experience in more than 4,200 patients. J Am Coll Surg 2009;208:896-905.

17. Chang WT, Kuo YT, Lee KT, et al. The value of primary vascular stents in management of early portal vein stenosis after liver transplantation. Kaohsiung J Med Sci 2016;32:128-34.

18. Glanemann M, Settmacher U, Stange B, et al. Caval complications after orthotopic liver transplantation. Transplant Proc 2000;32:539-40.

19. Korda D, Deák PÁ, Kiss G, et al. Management of portal hypertension after liver transplantation. Transplant Proc 2017;49:1530-4.

20. Shaheen AA, Myers RP. Diagnostic accuracy of the aspartate aminotransferase-to-platelet ratio index for the prediction of hepatitis C-related fibrosis: a systematic review. Hepatology 2007;46:912-21.

21. Sterling RK, Lissen E, Clumeck N, et al. Development of a simple noninvasive index to predict significant fibrosis in patients with HIV/HCV coinfection. Hepatology 2006; 43:1317-25.

22. European Association for the Study of the Liver. EASL clinical practice guidelines on the management of ascites, spontaneous bacterial peritonitis, and hepatorenal syndrome in cirrhosis. J Hepatol 2010;53:397-417.

23. Borroni G, Ceriani R, Cazzaniga M, et al. Comparison of simple tests for the non-invasive diagnosis of clinically silent cirrhosis in chronic hepatitis C. Aliment Pharmacol Ther 2006;24:797-804.

24. Rochon J, Gondan M, Kieser M. To test or not to test: preliminary assessment of normality when comparing two independent samples. BMC Med Res Methodol 2012;12:81.

25. Carrión JA, Navasa M, Bosch J, et al. Transient elastography for diagnosis of advanced fibrosis and portal hypertension in patients with hepatitis $\mathrm{C}$ recurrence after 
liver transplantation. Liver Transpl 2006;12:1791-8.

26. Corpechot C, Carrat F, Poujol-Robert A, et al.

Noninvasive elastography-based assessment of liver fibrosis progression and prognosis in primary biliary cirrhosis.

Hepatology 2012;56:198-208.

doi: $10.21037 / \operatorname{tgh}-19-343$

Cite this article as: Friedrich K, Mehrabi A, Pfeiffenberger J, Rupp C, Weiss KH, Mieth M. Spleen transient elastography predicts actuarial survival after liver transplantation. Transl Gastroenterol Hepatol 2022;7:31.
27. Colecchia A, Ravaioli F, Marasco G, et al. A combined model based on spleen stiffness measurement and Baveno VI criteria to rule out high-risk varices in advanced chronic liver disease. J Hepatol 2018;69:308-17. 